\title{
Influences of remote ischemic preconditioning on postoperative delirium and cognitive dysfunction in adults after cardiac surgery: a meta-analysis of randomized controlled trials
}

\author{
Yuchen Jing ${ }^{1}$, Bai Gao ${ }^{2}$ and Xi Li ${ }^{1 *}$ (i)
}

\begin{abstract}
Background: Remote ischemic preconditioning (RIPC) has been suggested to confer neuroprotective effect. However, influences of RIPC on postoperative delirium (POD) and cognitive dysfunction (POCD) in adults after cardiac surgery are less known. We performed a meta-analysis of randomized controlled trials (RCTs) to evaluate the effects of RIPC on POD and POCD.

Methods: Relevant studies were obtained by search of PubMed, Embase, and Cochrane's Library databases. A random-effect model was used to pool the results.

Results: Ten RCTs including 2303 adults who received cardiac surgery were included. Pooled results showed that RIPC did not significantly affect the incidence of POD (six RCTs, odds ratio [OR] 1.07, 95\% confidence interval [CI] 0.81 to $1.40, P=0.65)$ with no significant heterogeneity $\left(P^{2}=0 \%\right)$. In addition, combined results showed that RIPC did not significantly reduce the incidence of POCD either (six RCTs, OR $0.64,95 \% \mathrm{Cl} 0.37$ to $1.11, P=0.11$ ) with moderate heterogeneity $\left(R^{2}=44 \%\right)$. Sensitivity analysis by excluding one RCT at a time showed consistent results ( $P$ values all > 0.05).

Conclusions: Current evidence from RCTs did not support that RIPC could prevent the incidence of POD or POCD in adults after cardiac surgery. Although these findings may be validated in large-scale RCTs, particularly for the results of POCD, based on these findings, RIPC should not be routinely used as a preventative measure for POD and POCD in adult patients after cardiac surgery.
\end{abstract}

Keywords: Remote ischemic preconditioning, Postoperative delirium, Postoperative cognitive dysfunction, Cardiac surgery, Meta-analysis

\footnotetext{
* Correspondence: xilicmu_88@21cn.com

${ }^{1}$ Department of Vascular Surgery, The First Affiliated Hospital of China

Medical University, No. 155 Nanjing Bei Street, Heping District, Shenyang

110001, China

Full list of author information is available at the end of the article
}

(c) The Author(s). 2021 Open Access This article is licensed under a Creative Commons Attribution 4.0 International License, which permits use, sharing, adaptation, distribution and reproduction in any medium or format, as long as you give appropriate credit to the original author(s) and the source, provide a link to the Creative Commons licence, and indicate if changes were made. The images or other third party material in this article are included in the article's Creative Commons licence, unless indicated otherwise in a credit line to the material. If material is not included in the article's Creative Commons licence and your intended use is not permitted by statutory regulation or exceeds the permitted use, you will need to obtain permission directly from the copyright holder. To view a copy of this licence, visit http://creativecommons.org/licenses/by/4.0/ The Creative Commons Public Domain Dedication waiver (http://creativecommons.org/publicdomain/zero/1.0/) applies to the data made available in this article, unless otherwise stated in a credit line to the data. 


\section{Introduction}

Postoperative delirium (POD) and postoperative cognitive dysfunction (POCD) are common postoperative cognitive disorders in patients following cardiac surgery with general anesthesia (Thiele et al., 2021; Kapoor, 2020). Clinically, POD is defined as a transient disturbance of the consciousness, attention, cognition, and perception of the patient, which could affect up to $50 \%$ of elderly patients after cardiac surgery such as coronary artery bypass grafting (CABG) (Duning et al., 2021; Sanson et al., 2018). As for POCD, it is typically presented as a decline in cognitive function after the surgery, which could affect both the young and old patients after cardiac surgery (Hua \& Min, 2020; Glumac et al., 2019). Previous studies have confirmed that both POD and POCD are associated with prolonged hospitalization, impaired functional ability, and increased mortality in patients after cardiac surgery (Goldberg et al., 2020; Labaste et al., 2020; Brown et al., 2018; Li et al., 2021). Therefore, development of a novel strategy to prevent the incidence of POD/POCD is of importance in clinical practice. Remote ischemic preconditioning (RIPC) refers to a strategy which confers protective efficacy to target organs by inducing short episodes of ischemia and reperfusion in distant tissue (Heusch et al., 2015; Pickard et al., 2015). Emerging evidence has indicated that RIPC during the perioperative period may reduce the incidence of postoperative complications in patients after cardiac surgery, such as acute kidney injury (Liu et al., 2021) and myocardial injury (Moscarelli et al., 2021). Interestingly, recent evidence shows that RIPC may be effective for slowing cognitive decline in patients with cerebral small-vessel disease (Wang et al., 2017), subcortical ischemic vascular dementia (Liao et al., 2019), and after ischemic stroke (Landman et al., 2019). However, previous studies have not fully determined whether RIPC is effective in reducing POD/POCD in patients after cardiac surgery (Jing \& Zheng, 2011; Joung et al., 2013; Meybohm et al., 2013; Hudetz et al., 2015; Meybohm et al., 2015; Brown, 2016; Kim et al., 2017; Meybohm et al., 2018; Gasparovic et al., 2019; Wang et al., 2019). Accordingly, we performed a meta-analysis of randomized controlled trials (RCTs) to systematically evaluate the potential influences of RIPC on postoperative cognitive complications in patients following cardiac surgery.

\section{Methods}

The PRISMA (Preferred Reporting Items for Systematic Reviews and Meta-Analyses) statement (Moher et al., 2009) and the Cochrane Handbook guidelines (Higgins \& Green, 2011) were followed during the designing and implementation of the study.

\section{Search strategy}

PubMed, Embase, and the Cochrane Library (Cochrane Center Register of Controlled Trials) databases were searched for relevant studies with a combined strategy of (1) "ischemic preconditioning" OR "remote ischemic preconditioning" OR "RIPC", (2) "cardiac surgery" OR "heart surgery" OR "postoperative" OR "cognition" OR "cognitive" OR "delirium" OR "dementia", and (3) "random" OR "randomized" OR "randomized" OR "randomly." Only clinical studies were considered. The references of related reviews and original articles were also searched as a complementation. The final database search was conducted on April 20, 2021.

\section{Study selection}

Studies that fulfilled the following criteria were included as follows: (1) articles published in English or Chinese, (2) designed as parallel-group RCTs, (3) included adult patients scheduled for open heart surgery who were randomly allocated to a RIPC treatment group or a control group, and (4) reported the incidence of POD and/or POCD in the perioperative periods. The diagnostic criteria of POD and POCD outcomes in the meta-analysis were in accordance with that applied in the included studies. Reviews, studies with children or neonates, studies of non-cardiac surgery, preclinical studies, observational studies, and repeated reports were excluded.

\section{Data extraction and quality assessment}

Database search, data extraction, and quality evaluation were conducted by two independent authors. If disagreement occurred, it was resolved by discussion with the corresponding author. We extracted data regarding study information (first author, publication year, and study country), study design (blind or open-label), patient information (number of participants, mean age, and sex), surgery type, perioperative anesthetics, and anesthesia depth monitoring, RIPC protocol, and diagnostic strategy for patients with POD and/or POCD. Quality evaluation was achieved using the Cochrane's Risk of Bias Tool (Higgins \& Green, 2011) according to the following aspects: (1) random sequence generation, (2) allocation concealment, (3) blinding of participants and personnel, (4) blinding of outcome assessors, (5) incomplete outcome data, (6) selective outcome reporting, and (7) other potential bias.

\section{Statistical analysis}

Incidence of POD and POCD was separately evaluated via odds ratios (ORs) and their 95\% confidence intervals (CIs) in this meta-analysis. We used the Cochrane's Q test to detect the heterogeneity (Higgins \& Thompson, 2002). The $I^{2}$ statistic was also calculated, and an $I^{2}>$ $50 \%$ reflected significant heterogeneity. Pooled analyses 
were calculated using a random-effect model because this method incorporates the influence of potential heterogeneity and retrieves a more generalized result (Higgins \& Green, 2011). Sensitivity analysis by excluding one study at a time was used to evaluate the influence of each study on the pooled results of the meta-analysis (Higgins \& Green, 2011). Publication bias was evaluated by visual inspection of funnel plots, and the Egger's regression asymmetry test (Egger et al., 1997). If high risk of publication bias was suggested, a "trim-and-fill" analysis was used for further evaluation, which estimates the influence of possible studies with negative findings on the meta-analysis outcome (Higgins \& Green, 2011). P values $<0.05$ were considered statistically significant. The RevMan (Version 5.1; Cochrane, Oxford, UK) and Stata software (Version 12.0; Stata, College Station, TX) were applied for statistical analyses.

\section{Results}

\section{Search results}

The process of database search and study identification was shown in Fig. 1. Briefly, 1124 articles were obtained through the database search, and 972 were retrieved after exclusion of duplicated records. Among them, 918 articles were subsequently excluded based on titles and abstracts primarily because these studies were irrelevant to the aim of the meta-analysis. Of the 54 articles that underwent full-text review, 44 were further excluded for the reasons presented in Fig. 1 Finally, 10 RCTs (Jing \& Zheng, 2011; Joung et al., 2013; Meybohm et al., 2013; Hudetz et al., 2015; Meybohm et al., 2015; Brown, 2016; Kim et al., 2017; Meybohm et al., 2018; Gasparovic et al., 2019; Wang et al., 2019) were included.

\section{Study characteristics}

Table 1 shows the characteristics of the included studies. Overall, 10 RCTs with 2303 patients were included in the current meta-analysis (Jing \& Zheng, 2011; Joung et al., 2013; Meybohm et al., 2013; Hudetz et al., 2015; Meybohm et al., 2015; Brown, 2016; Kim et al., 2017; Meybohm et al., 2018; Gasparovic et al., 2019; Wang et al., 2019). These studies were published between 2011 and 2019 and performed in China (Jing \& Zheng, 2011; Wang et al., 2019), Korea (Joung et al., 2013; Kim et al., 2017), Germany (Meybohm et al., 2013; Meybohm et al., 2015; Meybohm et al., 2018), and the USA (Hudetz

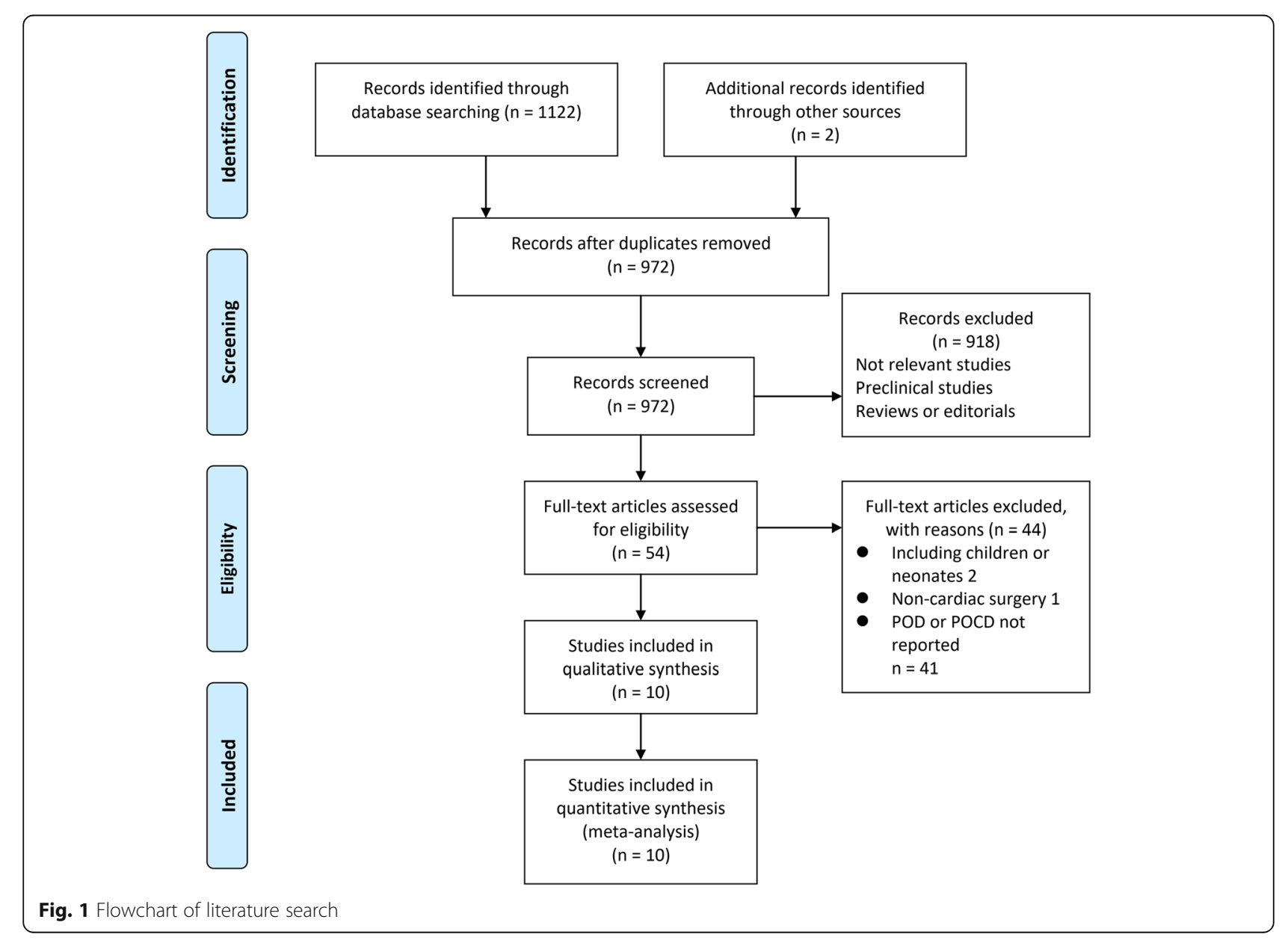




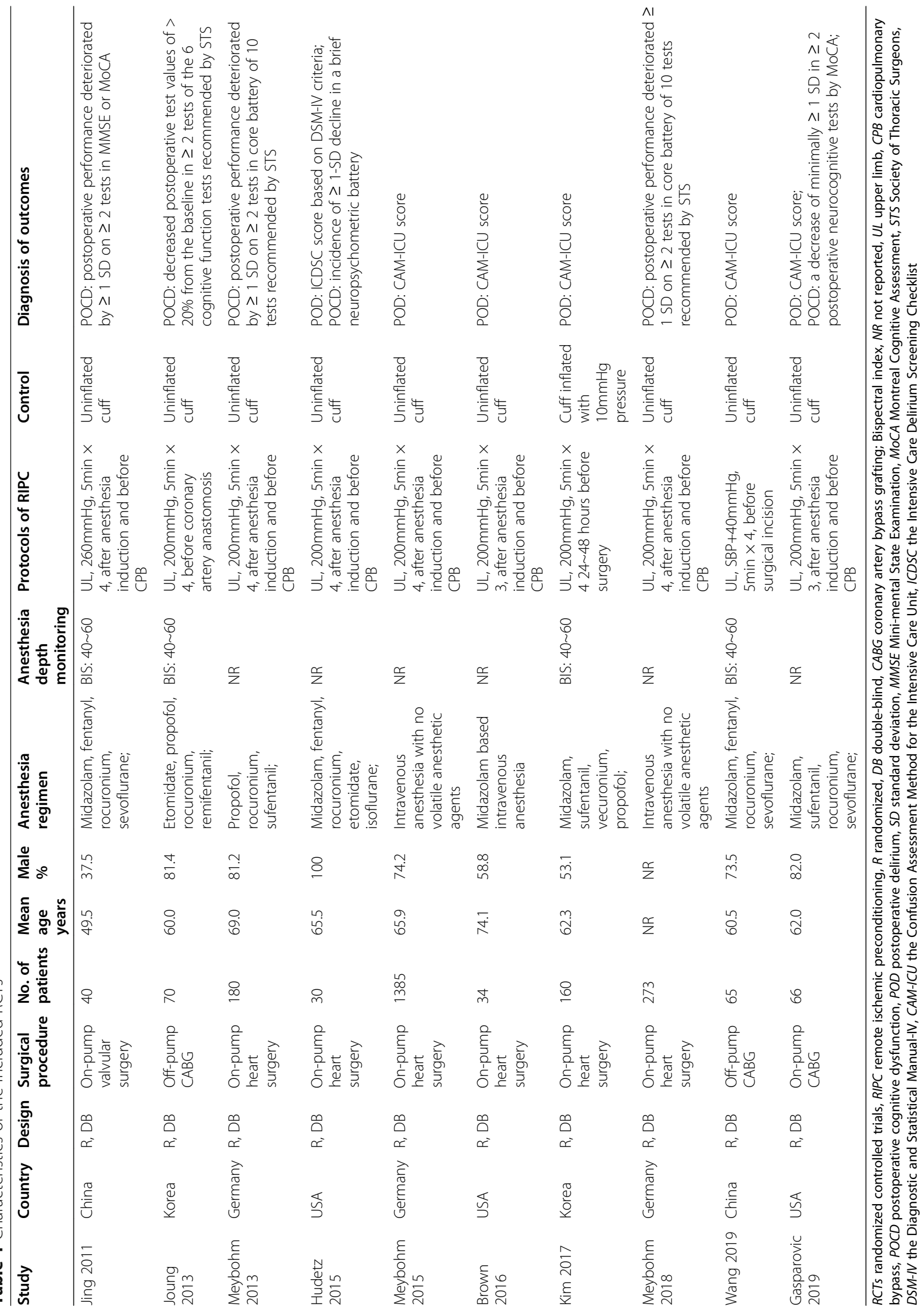


et al., 2015; Brown, 2016; Gasparovic et al., 2019), respectively. All of these studies were double-blinded RCTs. Eight studies included patients with on-pump heart surgeries (Jing \& Zheng, 2011; Meybohm et al., 2013; Hudetz et al., 2015; Meybohm et al., 2015; Brown, 2016; Kim et al., 2017; Meybohm et al., 2018; Gasparovic et al., 2019), while the remaining two included patients with off-pump surgeries (Joung et al., 2013; Wang et al., 2019). General anesthesia with intravenous anesthetics was applied in the included studies. In nine studies, RIPC was performed after anesthesia induction (acute RIPC) (Jing \& Zheng, 2011; Joung et al., 2013; Meybohm et al., 2013; Hudetz et al., 2015; Meybohm et al., 2015; Brown, 2016; Meybohm et al., 2018; Gasparovic et al., 2019; Wang et al., 2019), while in one study RIPC was performed 24 48h before the surgery (chronic RIPC) (Kim et al., 2017). The protocol of RIPC included 3 4 cycles of upper or lower limb ischemia ( $5 \mathrm{~min}$ of blood pressure cuff inflation to a pressure of $200 \mathrm{mmHg}$ or at least a pressure that was $40 \mathrm{mmHg}$ higher than the systolic arterial pressure), followed by $5 \sim 10 \mathrm{~min}$ reperfusion (with the cuff deflated). Uninflated cuffs were used on patients in the control group after anesthesia for studies evaluating the acute effect of RIPC (Jing \& Zheng, 2011; Joung et al., 2013; Meybohm et al., 2013; Hudetz et al., 2015; Meybohm et al., 2015; Brown, 2016; Meybohm et al., 2018; Gasparovic et al., 2019; Wang et al., 2019), while cuff inflated with $10 \mathrm{mmHg}$ pressure was applied for patients of control group in the only delayed-effect study (Kim et al., 2017). The outcome of POD was reported in six RCTs (Hudetz et al., 2015; Meybohm et al., 2015; Brown, 2016; Kim et al., 2017; Gasparovic et al., 2019; Wang et al., 2019), which were diagnosed based on instruments of CAM-ICU (Meybohm et al., 2015; Brown, 2016; Kim et al., 2017; Gasparovic et al., 2019; Wang et al., 2019) or ICDSC score (Hudetz et al., 2015). The incidence of POCD events was also reported in six
RCTs (Jing \& Zheng, 2011; Joung et al., 2013; Meybohm et al., 2013; Hudetz et al., 2015; Meybohm et al., 2018; Gasparovic et al., 2019), most of which were diagnosed by the standard deviation (SD) criteria (Jing \& Zheng, 2011; Meybohm et al., 2013; Hudetz et al., 2015; Meybohm et al., 2018; Gasparovic et al., 2019). Specifically, POCD was defined as postoperative performance deterioration by $\geq 1 \mathrm{SD}$ on $\geq 2$ tests in four studies (Jing \& Zheng, 2011; Meybohm et al., 2013; Meybohm et al., 2018; Gasparovic et al., 2019), by $>20 \%$ on $\geq 2$ cognitive tests in one study (Joung et al., 2013), and by $\geq 1$ SD on $\geq 1$ cognitive test in the other study (Hudetz et al., 2015). Patients with POD and POCD were identified within 5 7 days after surgery in all of the included studies.

\section{Data quality}

Table 2 shows the details of study quality evaluation. All of the included RCTs were double-blind studies. Methods of random sequence generation were reported in seven RCTs (Jing \& Zheng, 2011; Joung et al., 2013; Meybohm et al., 2015; Brown, 2016; Meybohm et al., 2018; Gasparovic et al., 2019; Wang et al., 2019), and information of allocation concealment was reported in six RCTs (Meybohm et al., 2013; Hudetz et al., 2015; Meybohm et al., 2015; Kim et al., 2017; Meybohm et al., 2018; Gasparovic et al., 2019). The overall quality score varied between 5 and 7, indicating generally good study quality.

\section{Meta-analysis results}

Pooled results showed that RIPC did not significantly affect the incidence of POD (six RCTs, OR 1.07, 95\% CI 0.81 to $1.40, P=0.65$; Fig. 2 A) with no significant heterogeneity $\left(P\right.$ for Cochrane's $Q$ test $=0.78, I^{2}=$ $0 \%)$. Sensitivity analysis by excluding one study at a time showed consistent results (Table 3). In addition,

Table 2 Details of quality evaluation for the included RCTs according to the Cochrane's Risk of Bias Tool

\begin{tabular}{|c|c|c|c|c|c|c|c|c|}
\hline Study & $\begin{array}{l}\text { Random } \\
\text { sequence } \\
\text { generation }\end{array}$ & $\begin{array}{l}\text { Allocation } \\
\text { concealment }\end{array}$ & $\begin{array}{l}\text { Blinding of } \\
\text { participants }\end{array}$ & $\begin{array}{l}\text { Blinding of } \\
\text { outcome } \\
\text { assessment }\end{array}$ & $\begin{array}{l}\text { Incomplete outcome } \\
\text { data addressed }\end{array}$ & $\begin{array}{l}\text { Selective } \\
\text { reporting }\end{array}$ & $\begin{array}{l}\text { Other } \\
\text { sources } \\
\text { of bias }\end{array}$ & Total \\
\hline Jing 2011 & Low & Unclear & Low & Low & Low & Low & Low & 6 \\
\hline Joung 2013 & Low & Unclear & Low & Low & Low & Low & Low & 6 \\
\hline Meybohm 2013 & Unclear & Low & Low & Low & Low & Low & Low & 6 \\
\hline Hudetz 2015 & Unclear & Low & Low & Low & Low & Low & Low & 6 \\
\hline Meybohm 2015 & Low & Low & Low & Low & Low & Low & Low & 7 \\
\hline Brown 2016 & Unclear & Unclear & Low & Low & Low & Low & Low & 5 \\
\hline Kim 2017 & Low & Low & Low & Low & Low & Low & Low & 7 \\
\hline Meybohm 2018 & Low & Low & Low & Low & Low & Low & Low & 7 \\
\hline Wang 2019 & Low & Unclear & Low & Low & Low & Low & Low & 6 \\
\hline Gasparovic 2019 & Low & Low & Low & Low & Low & Low & Low & 7 \\
\hline
\end{tabular}




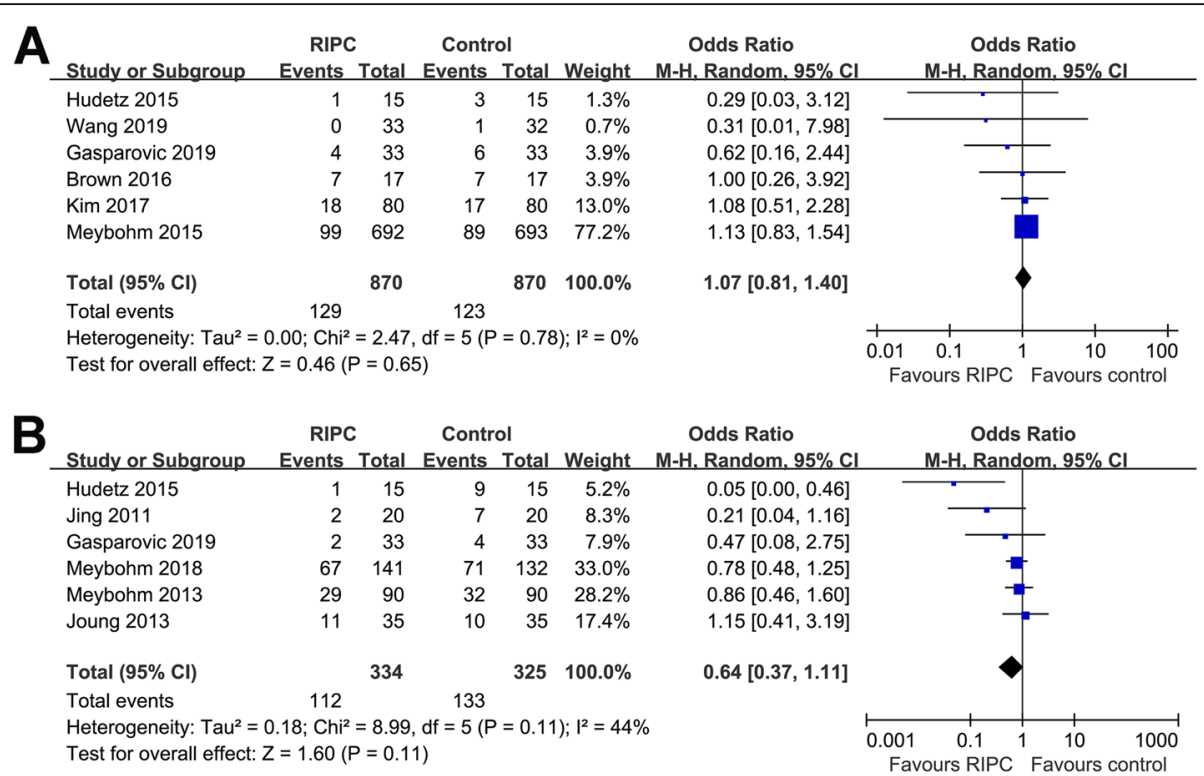

Fig. 2 Forest plots for the meta-analysis of effects of RIPC on POD and POCD after cardiac surgery. A Forest plots for the meta-analysis of RIPC on POD and $\mathbf{B}$ forest plots for the meta-analysis of RIPC on POCD

combined results showed that RIPC did not significantly reduce the incidence of POCD either (six RCTs, OR $0.64,95 \%$ CI 0.37 to $1.11, P=0.11$; Fig. $2 \mathrm{~B})$ with moderate heterogeneity ( $P$ for Cochrane's $Q$ test $\left.=0.11, I^{2}=44 \%\right)$. Sensitivity analysis by omitting one study at a time also did not significantly affect the results (Table 3). Of note, the heterogeneity among the included RCTs for the meta-analysis of POCD was substantially reduced $\left(I^{2}=0 \%\right)$ after excluding the study by Hudetz 2015 (Hudetz et al., 2015), suggesting this study was the major contributor to the heterogeneity.

\section{Publication bias}

The funnel plots for the meta-analysis of POD were symmetrical, suggesting low-risk of publication bias (Fig. 3A). The funnel plots for the meta-analysis of POCD were asymmetrical on visual inspection, suggesting the potential risk of publication bias (Fig. 3B). Egger's regression tests were not performed since only six RCTs were available for each outcome. We therefore performed a trim-and-fill analysis for the outcome of POCD. As shown in Fig. 3B, incorporating the hypothesized study (black circle) achieved symmetry of the funnel plots, and the

Table 3 Sensitivity analyses

\begin{tabular}{|c|c|c|c|c|}
\hline Study excluded & OR $(95 \% \mathrm{Cl})$ & $I^{2}(\%)$ & $P$ for Cochrane's $Q$ test & $P$ for overall effect \\
\hline \multicolumn{5}{|c|}{ Influence of RIPC on POD } \\
\hline Hudetz 2015 & $1.08[0.83,1.42]$ & 0 & 0.86 & 0.56 \\
\hline Meybohm 2015 & $0.86[0.49,1.52]$ & 0 & 0.77 & 0.61 \\
\hline Brown 2016 & $1.07[0.81,1.41]$ & 0 & 0.65 & 0.64 \\
\hline Kim 2017 & $1.06[0.80,1.42]$ & 0 & 0.65 & 0.68 \\
\hline Wang 2019 & $1.07[0.82,1.41]$ & 0 & 0.75 & 0.60 \\
\hline Gasparovic 2019 & $1.09[0.83,1.43]$ & 0 & 0.76 & 0.55 \\
\hline \multicolumn{5}{|c|}{ Influence of RIPC on POCD } \\
\hline Jing 2011 & $0.72[0.42,1.23]$ & 41 & 0.15 & 0.23 \\
\hline Joung 2013 & $0.54[0.28,1.04]$ & 51 & 0.09 & 0.07 \\
\hline Meybohm 2013 & $0.50[0.22,1.13]$ & 54 & 0.07 & 0.10 \\
\hline Hudetz 2015 & $0.78[0.56,1.10]$ & 0 & 0.52 & 0.15 \\
\hline Meybohm 2018 & $0.50[0.21,1.19]$ & 55 & 0.06 & 0.12 \\
\hline Gasparovic 2019 & $0.64[0.34,1.18]$ & 54 & 0.07 & 0.15 \\
\hline
\end{tabular}




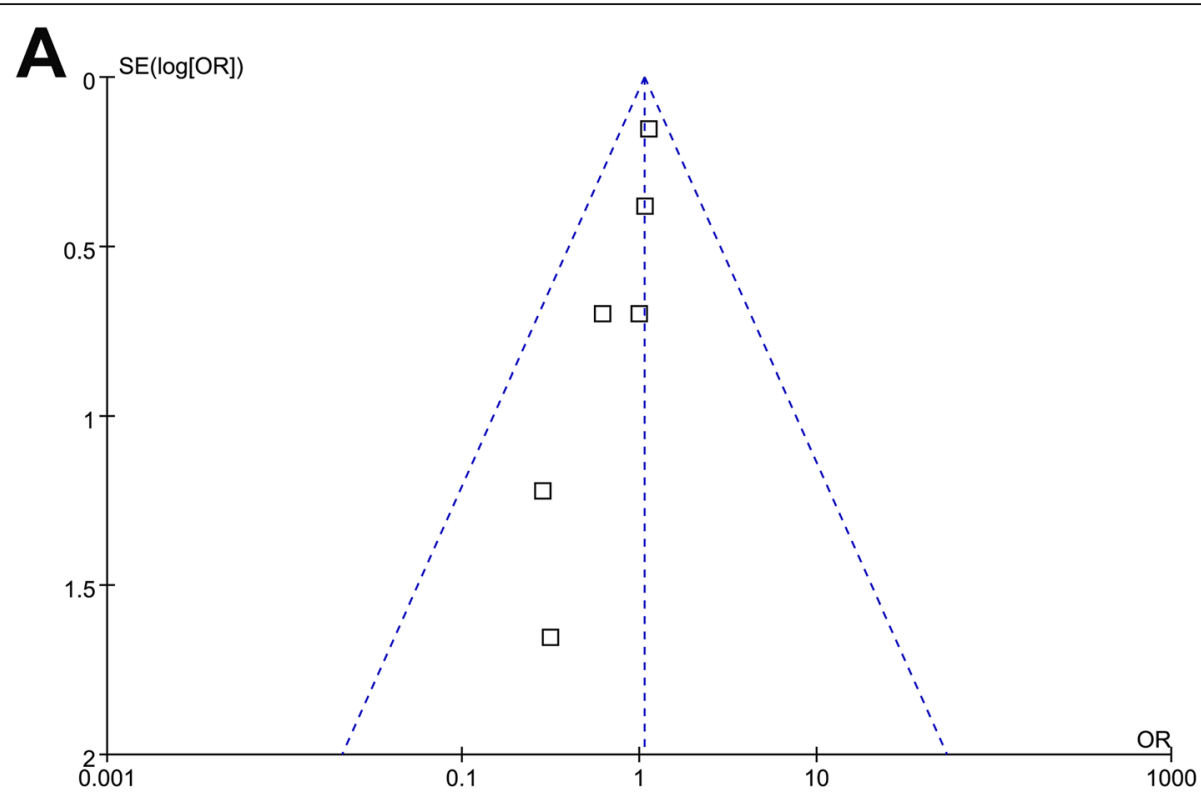

B

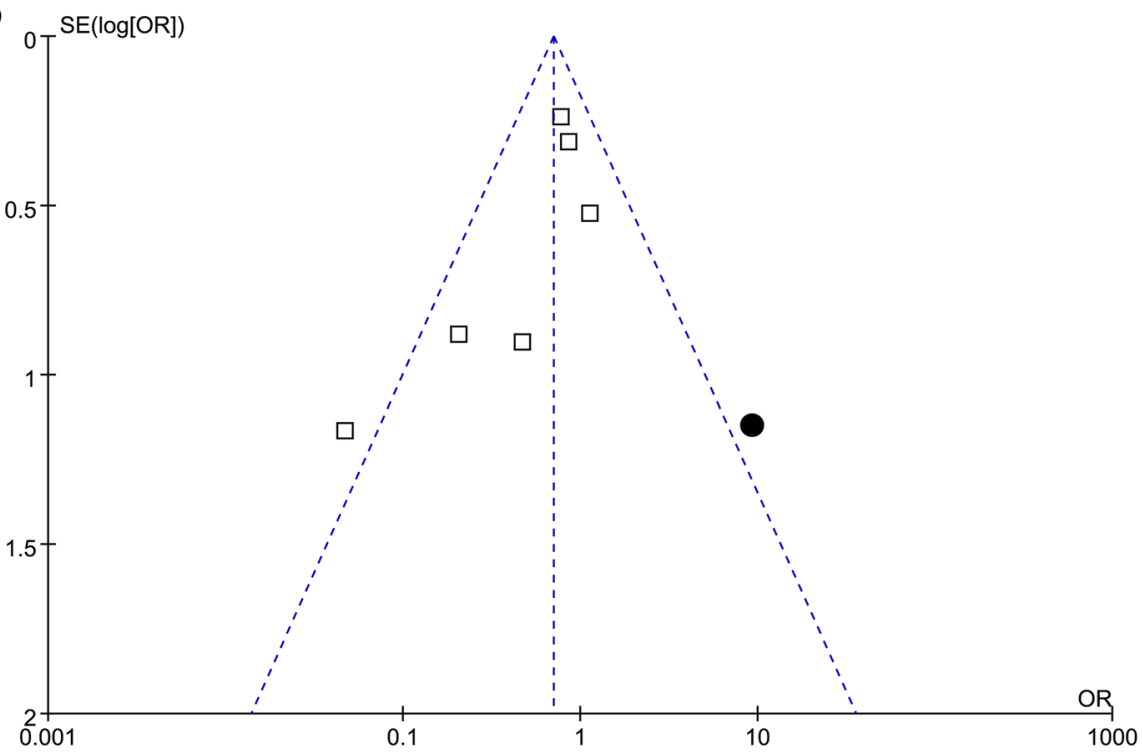

Fig. 3 Funnel plots for the effects of RIPC on POD and POCD after cardiac surgery. A Funnel plots for the effect of RIPC on POD and B funnel plots with "trim-and-fill" analysis for the effect of RIPC on POCD (black circle indicates the hypothesized study to achieve the symmetry of the funnel plots)

results of the meta-analysis remained consistent after including this study (OR $0.72,95 \%$ CI 0.36 to 1.43 , $\left.P=0.35 ; I^{2}=61 \%\right)$.

\section{Discussion}

In this study, by pooling the results of available RCTs, the results of the meta-analysis showed that RIPC does not significantly reduce the incidence of POD or POCD in adults following cardiac surgery. To the best of our knowledge, this is the first meta-analysis which summarized the current knowledge regarding the influence of RIPC on postoperative cognitive complications in adults after cardiac surgery. Based on these findings, RIPC should not be routinely used as a preventative measure for POD and POCD in adult patients after cardiac surgery.

For the meta-analysis evaluating the potential effect of RIPC on POD, six RCTs were included (Hudetz et al., 2015; Meybohm et al., 2015; Brown, 2016; Kim et al., 2017; Gasparovic et al., 2019; Wang et al., 
2019). Although one of the largest RCT primarily contributed to the results of the meta-analysis (Meybohm et al., 2015), results of the other small-scale RCTs were all consistent, leading to a very low heterogeneity among the included studies $\left(I^{2}=0 \%\right)$. Unsurprisingly, sensitivity analysis by excluding one study at a time showed consistent results, which further confirmed the robustness of the finding. Taken together, results of our meta-analysis confirmed that in adults following cardiac surgery, RIPC is not effective to reduce the incidence of POD. Currently, the mechanisms underlying the pathogenesis of POD remain largely unknown. It is generally accepted that multiple mechanisms may be involved in the pathogenesis of POD, such as inflammation, activated cytokines, and the neurochemical imbalances that affect neurotransmission (Oh \& Park, 2019). Moreover, multiple risk factors have been identified underlying the development of POD, such as advanced age, preexisting cerebral and affective disorders, preoperative fluid fasting and dehydration, perioperative bleeding and hypovolemia, hyponatremia or hypernatremia, and the use of drugs with anticholinergic effects (Aldecoa et al., 2017). The physiological efficacy of RIPC is to meliorate the extent of ischemic-reperfusion injury, which may be simply not adequate to prevent multiple possible mechanisms that involved in the pathogenesis of POD (Pieri et al., 2020).

Similarly, six RCTs (Jing \& Zheng, 2011; Joung et al., 2013; Meybohm et al., 2013; Hudetz et al., 2015; Meybohm et al., 2018; Gasparovic et al., 2019) were available for the meta-analysis evaluating the efficacy of RIPC on POCD after cardiac surgery. The sample sizes of the included RCTs were generally small, with a total of 659 patients observed and 245 with POCD. Pooled results showed that RIPC was not associated with significantly reduced POCD after cardiac surgery, although moderate heterogeneity was noticed. Sensitivity analysis by omitting one study at a time also showed consistent results, suggesting the robustness of the findings. However, it should be noticed that excluding the study by Hudetz et al. (Hudetz et al., 2015) substantially reduced the heterogeneity of the meta-analysis $\left(I^{2}\right.$ from 44 to $0 \%$ ), suggesting that this study is the major source of heterogeneity. Interestingly, the study by Hudetz et al. is different from others in the diagnostic criteria for POCD. POCD was defined as a substantial decline of performance on $\geq 1$ cognitive test in this study (Hudetz et al., 2015), while in the other studies, substantial declined performance on $\geq 2$ cognitive test were requested. The relative loose criteria for the diagnosis of POCD in this study may lead to more patients diagnosed as POCD, and this is the only included RCT which showed that RIPC significantly reduced POCD after cardiac surgery. These findings may suggest that the effect of RIPC on POCD following cardiac surgery may be different according to the different diagnostic criteria for POCD applied among the included studies. However, in view of the emerged consensus regimens for neurocognitive testing and diagnostic criteria for POCD, such as the Recommendations for the Nomenclature of Cognitive Change associated with Anaesthesia and Surgery (2018) (Evered et al., 2018), studies evaluating the possible preventative strategies for POCD diagnosed with standardized criteria are needed. The result of this metaanalysis highlighted the important influence of definitions of POCD on the interpretation for studies that evaluated the potential preventative strategies for POCD (Needham et al., 2017).

The strengths of the current meta-analysis included rigorous literature search, strict inclusion and exclusion criteria, and performance of multiple sensitivity analysis to evaluate the potential source of heterogeneity. Besides, this study also has limitations. Firstly, as previously indicated, regimens for neurocognitive testing and diagnostic criteria for POCD varied among the included studies, and the difference in the definition of POCD may affect the results of the meta-analysis. Furthermore, we did not have access to the individual patient data. Accordingly, potential influences of patient or study characteristics on the outcomes of the meta-analysis could not be evaluated. Moreover, the sample sizes of the included RCTs varied significantly, particularly for the outcome of POD. The study with largest sample size (Meybohm et al., 2015) comprised over half of the included patients of the meta-analysis, which may primarily contribute to the overall results. Finally, the potential risk of publication bias was noticed for the outcome of POCD. However, further "trim-and-fill" analysis by incorporating the hypothesized studies with a positive result did not significantly change the overall results of the meta-analysis.

\section{Conclusion}

In conclusion, results of this meta-analysis showed that RIPC does not significantly reduce the incidence of POD or POCD in adults following cardiac surgery. Although these findings may be validated in large-scale RCTs, particularly for the results of POCD, based on these findings, RIPC should not be routinely used as a preventative measure for POD and POCD in adult patients after cardiac surgery.

\section{Abbreviations}

POCD: Postoperative cognitive dysfunction; POD: Postoperative delirium; CABG: Coronary artery bypass grafting; RIPC: Remote ischemic preconditioning; RCT: Randomized controlled trial

\section{Acknowledgements}

The authors would like to thank the authors of the primary studies. 


\section{Authors' contributions}

$Y J$ and $X L$ contributed to the conception and design of the study. YJ and BG performed database search, study identification, data extraction, and statistical analysis. YJ wrote the first draft of the manuscript. The authors contributed to manuscript revision, and read and approved the submitted version.

\section{Funding}

No funding was received for this study.

\section{Availability of data and materials}

The datasets used and/or analyzed during the current study are available from the corresponding author on reasonable request.

\section{Declarations}

Ethics approval and consent to participate

Not applicable.

\section{Consent for publication}

Not applicable.

\section{Competing interests}

The authors declare that they have no competing interests.

\section{Author details}

${ }^{1}$ Department of Vascular Surgery, The First Affiliated Hospital of China Medical University, No. 155 Nanjing Bei Street, Heping District, Shenyang 110001, China. ${ }^{2}$ Department of Neurology, Shengjing Hospital Affiliated to China Medical University, Shenyang 110004, China.

\section{Received: 4 July 2021 Accepted: 25 August 2021}

\section{Published online: 10 December 2021}

\section{References}

Aldecoa C, Bettelli G, Bilotta F, Sanders RD, Audisio R, Borozdina A, et al. European Society of Anaesthesiology evidence-based and consensus-based guideline on postoperative delirium. Eur J Anaesthesiol. 2017;34(4):192-214. https://doi.org/10.1097/EJA.0000000000000594.

Brown $\mathrm{CH}$. The effect of remote ischemic preconditioning on delirium after cardiac surgery. Anesth Analg. 2016;122(5):S64. https://doi.org/10.1213/01.ane. 0000499505.96779.a0.

Brown CH, Probert J, Healy R, Parish M, Nomura Y, Yamaguchi A, et al. Cognitive decline after delirium in patients undergoing cardiac surgery. Anesthesiology. 2018;129(3):406-16. https://doi.org/10.1097/ALN.0000000000002253.

Duning T, Ilting-Reuke K, Beckhuis M, Oswald D. Postoperative delirium treatment and prevention. Curr Opin Anaesthesiol. 2021;34(1):27-32. https:// doi.org/10.1097/ACO.0000000000000939.

Egger M, Davey Smith G, Schneider M, Minder C. Bias in meta-analysis detected by a simple, graphical test. BMJ. 1997;315(7109):629-34.

Evered L, Silbert B, Knopman DS, Scott DA, DeKosky ST, Rasmussen LS, et al. Recommendations for the nomenclature of cognitive change associated with anaesthesia and surgery-2018. Anesthesiology. 2018;129(5):872-9. https://doi.org/10.1097/ALN.0000000000002334.

Gasparovic H, Kopjar T, Rados M, Anticevic A, Malojcic B, Ivancan V, et al. Impact of remote ischemic preconditioning preceding coronary artery bypass grafting on inducing neuroprotection. J Thorac Cardiovasc Surg. 2019;157(4): 1466-76 e1463. https://doi.org/10.1016/j.jtcvs.2018.08.116.

Glumac S, Kardum G, Karanovic N. Postoperative cognitive decline after cardiac surgery: a narrative review of current knowledge in 2019. Med Sci Monit. 2019;25:3262-70. https://doi.org/10.12659/MSM.914435.

Goldberg TE, Chen C, Wang Y, Jung E, Swanson A, Ing C, et al. Association of delirium with long-term cognitive decline: a meta-analysis. JAMA Neurol. 2020;77(11):1373-81. https://doi.org/10.1001/jamaneurol.2020.2273.

Heusch G, Botker HE, Przyklenk K, Redington A, Yellon D. Remote ischemic conditioning. J Am Coll Cardiol. 2015;65(2):177-95. https://doi.org/10.1016/j.ja cc.2014.10.031.

Higgins J, Green S (2011) Cochrane Handbook for Systematic Reviews of Interventions Version 5.1.0. The Cochrane Collaboration www.cochraneha ndbook.org
Higgins JP, Thompson SG. Quantifying heterogeneity in a meta-analysis. Stat Med. 2002:21(11):1539-58. https://doi.org/10.1002/sim.1186.

Hua M, Min J. Postoperative cognitive dysfunction and the protective effects of enriched environment: a systematic review. Neurodegener Dis. 2020;20(4): 113-22. https://doi.org/10.1159/000513196.

Hudetz JA, Patterson KM, lqbal Z, Gandhi SD, Pagel PS. Remote ischemic preconditioning prevents deterioration of short-term postoperative cognitive function after cardiac surgery using cardiopulmonary bypass: results of a pilot investigation. J Cardiothorac Vasc Anesth. 2015;29(2):382-8. https://doi. org/10.1053/j.jvca.2014.07.012.

Jing GX, Zheng LL. Protective effects of remote ischemic preconditioning on cerebral injury in patients undergoing cardiac valve replacement with CPB. J Xi'an Jiaotong Univ (Medical Sciences). 2011;32(4):473-5.

Joung KW, Rhim JH, Chin JH, Kim WJ, Choi DK, Lee EH, et al. Effect of remote ischemic preconditioning on cognitive function after off-pump coronary artery bypass graft: a pilot study. Korean J Anesthesiol. 2013;65(5):418-24 https://doi.org/10.4097/kjae.2013.65.5.418.

Kapoor MC. Neurological dysfunction after cardiac surgery and cardiac intensive care admission: a narrative review part 1: the problem; nomenclature; delirium and postoperative neurocognitive disorder; and the role of cardiac surgery and anesthesia. Ann Card Anaesth. 2020;23(4):383-90. https://doi. org/10.4103/aca.ACA_138_19.

Kim TK, Min JJ, Cho YJ, Hausenloy DJ, Ahn H, Kim KH, et al. Effects of delayed remote ischemic preconditioning on peri-operative myocardial injury in patients undergoing cardiac surgery - a randomized controlled trial. Int J Cardiol. 2017;227:511-5. https://doi.org/10.1016/j.ijcard.2016.10.111.

Labaste F, Porterie J, Bousquet P, Marcheix B, Sanchez-Verlaan P, Frances B, et al. Postoperative delirium is a risk factor of poor evolution three years after cardiac surgery: an observational cohort study. Clin Interv Aging. 2020;15: 2375-81. https://doi.org/10.2147/CIA.S265797.

Landman TRJ, Schoon Y, Warle MC, de Leeuw FE, Thijssen DHJ. Remote ischemic conditioning as an additional treatment for acute ischemic stroke. Stroke. 2019;50(7):1934-9. https://doi.org/10.1161/STROKEAHA.119.025494.

Li HC, Wei YC, Hsu RB, Chi NH, Wang SS, Chen YS, et al. Surviving and thriving 1 year after cardiac surgery: frailty and delirium matter. Ann Thorac Surg. 2021; 111(5):1578-84. https://doi.org/10.1016/j.athoracsur.2020.07.015.

Liao Z, Bu Y, Li M, Han R, Zhang N, Hao J, et al. Remote ischemic conditioning improves cognition in patients with subcortical ischemic vascular dementia. BMC Neurol. 2019;19(1):206. https://doi.org/10.1186/ s12883-019-1435-y.

Liu Z, Zhao Y, Lei M, Zhao G, Li D, Sun R, et al. Remote ischemic preconditioning to prevent acute kidney injury after cardiac surgery: a meta-analysis of randomized controlled trials. Front Cardiovasc Med. 2021;8:601470. https:// doi.org/10.3389/fcvm.2021.601470

Meybohm P, Bein B, Brosteanu O, Cremer J, Gruenewald M, Stoppe C, et al. A multicenter trial of remote ischemic preconditioning for heart surgery. $\mathrm{N}$ Engl J Med. 2015;373(15):1397-407. https://doi.org/10.1056/NEJMoa1413579.

Meybohm P, Kohlhaas M, Stoppe C, Gruenewald M, Renner J, Bein B, et al. RIPHeart (Remote Ischemic Preconditioning for Heart Surgery) Study: myocardial dysfunction, postoperative neurocognitive dysfunction, and 1 year follow-up. J Am Heart Assoc. 2018;7(7):e008077. https://doi.org/10.1161/ JAHA.117.008077

Meybohm P, Renner J, Broch O, Caliebe D, Albrecht M, Cremer J, et al. Postoperative neurocognitive dysfunction in patients undergoing cardiac surgery after remote ischemic preconditioning: a double-blind randomized controlled pilot study. PLoS One. 2013;8(5):e64743. https://doi.org/10.1371/ journal.pone.0064743.

Moher D, Liberati A, Tetzlaff J, Altman DG. Preferred reporting items for systematic reviews and meta-analyses: the PRISMA statement. BMJ. 2009;339: b2535. https://doi.org/10.1136/bmj.b2535.

Moscarelli M, Angelini GD, Emanueli C, Suleiman S, Pepe M, Contegiacomo G, et al. Remote ischemic preconditioning in isolated valve intervention. A pooled meta-analysis. Int J Cardiol. 2021;324:146-51. https://doi.org/10.1016/j. ijcard.2020.10.020.

Needham MJ, Webb CE, Bryden DC. Postoperative cognitive dysfunction and dementia: what we need to know and do. Br J Anaesth. 2017;119(suppl_1): i1 15-25. https://doi.org/10.1093/bja/aex354.

Oh ST, Park JY. Postoperative delirium. Korean J Anesthesiol. 2019;72(1):4-12. https://doi.org/10.4097/kja.d.18.00073.1.

Pickard JM, Botker HE, Crimi G, Davidson B, Davidson SM, Dutka D, et al. Remote ischemic conditioning: from experimental observation to clinical application: 
report from the 8th Biennial Hatter Cardiovascular Institute Workshop. Basic Res Cardiol. 2015;110(1):453. https://doi.org/10.1007/s00395-014-0453-6.

Pieri M, De Simone A, Rose S, De Domenico P, Lembo R, Denaro G, et al. Trials focusing on prevention and treatment of delirium after cardiac surgery: a systematic review of randomized evidence. J Cardiothorac Vasc Anesth. 2020; 34(6):1641-54. https://doi.org/10.1053/j.jvca.2019.09.028.

Sanson G, Khlopenyuk Y, Milocco S, Sartori M, Dreas L, Fabiani A. Delirium after cardiac surgery. Incidence, phenotypes, predisposing and precipitating risk factors, and effects. Heart Lung. 2018;47(4):408-17. https://doi.org/10.1016/j. hrtlng.2018.04.005.

Thiele RH, Theodore DJ, Gan TJ. Outcome of organ dysfunction in the perioperative period. Anesth Analg. 2021. https://doi.org/10.1213/ANE. 0000000000005603

Wang H, Lyu Y, Liao Q, Jin L, Xu L, Hu Y, et al. Effects of remote ischemic preconditioning in patients undergoing off-pump coronary artery bypass graft surgery. Front Physiol. 2019;10:495. https://doi.org/10.3389/fphys.2019. 00495.

Wang Y, Meng R, Song H, Liu G, Hua Y, Cui D, et al. Remote ischemic conditioning may improve outcomes of patients with cerebral small-vessel disease. Stroke. 2017;48(11):3064-72. https://doi.org/10.1161/STROKEAHA.117. 017691.

\section{Publisher's Note}

Springer Nature remains neutral with regard to jurisdictional claims in published maps and institutional affiliations.

Ready to submit your research? Choose BMC and benefit from:

- fast, convenient online submission

- thorough peer review by experienced researchers in your field

- rapid publication on acceptance

- support for research data, including large and complex data types

- gold Open Access which fosters wider collaboration and increased citations

- maximum visibility for your research: over $100 \mathrm{M}$ website views per year

At $\mathrm{BMC}$, research is always in progress.

Learn more biomedcentral.com/submissions 